\title{
A Case of Atlanto-Axial Joint Subluxation Following Tonsillectomy in Patient of Tonsillar Cancer with Preoperative Radiotherapy: Grisel's Syndrome
}

\author{
Yoon Seok Choi ${ }^{1}$, Chang Hoon Bae ${ }^{1}$, Yong-Dae Kim ${ }^{1,2}$, and Si-Youn Song ${ }^{1}$ \\ ${ }^{I}$ Department of Otorhinolaryngology-Head and Neck Surgery, College of Medicine, Yeungnam University, Daegu; and \\ ${ }^{2}$ Regional Center for Respiratory Diseases, Yeungnam University Medical Center, Daegu, Korea
}

\begin{abstract}
방사선 치료를 받은 편도암 환자에서 편도절제술 후 발생한 환-축추 관절 아탈구 1 예: 그리즐 증후군
최윤석 ${ }^{1} \cdot$ 배창훈 $^{1} \cdot$ 김용대 ${ }^{1,2} \cdot$ 송시연

영남대학교 의과대학 이비인후-두경부외과학교실, ${ }^{1}$ 영남대학교병원 권역 호흡기 전문질환센터리
\end{abstract}

\author{
Received August 31, 2015 \\ Revised October 22, 2015 \\ Accepted October 27, 2015 \\ Address for correspondence \\ Si-Youn Song, MD, PhD \\ Department of Otorhinolaryngology- \\ Head and Neck Surgery, \\ College of Medicine, \\ Yeungnam University, \\ 170 Hyeonchung-ro, Nam-gu, \\ Daegu 42415, Korea \\ Tel $+82-53-620-3782$ \\ Fax $+82-53-628-7884$ \\ E-mailssykhs@med.yu.ac.kr
}

\begin{abstract}
Grisel's syndrome, defined as the atlanto-axial joint subluxation not associated with a trauma or bone disease, is a rare complication following operative procedure and/or infections of the upper aerodigestive tract. Pathogenetically, it may occur in association with any condition that results in hyperemia and pathological relaxation of the transverse ligament of the atlanto-axial joint. When an inflammation heals, Grisel's syndrome can probably result in a fixation in the rotated position. It is diagnosed by physical and radiological findings. Early management, consisting of cervical immobilization and medical treatment, is considered a key factor for satisfactory outcome. Inappropriate treatment can result in a catastrophic consequence. Recently, we experienced a case of Grisel's syndrome following tonsillectomy in a patient with left palatine tonsillar cancer with preoperative radiotherapy. We report this case with a literature review. Korean J Otorhinolaryngol-Head Neck Surg 2016;59(8):604-8
\end{abstract}

Key Words Atlanto-axial joint subluxation · Radiotherapy · Tonsillar cancer · Tonsillectomy.

\section{서 론}

그리즐 증후군(Grisel's syndrome)은 비외상성 환-축추 관 절의 아탈구를 일컬으며," 이비인후과 질환과 연관되어 발생

하는 경우는 매우 드물다. 환-축추 관절의 횡인대의 병적 이 완과 충혈을 유발하는 다양한 질환에 의해 이차적으로 발생 하는데 주로 알려진 원인 질환으로는 상기도 감염, 후인두부 농양, 중이염, 및 편도와 아데노이드 수술을 포함한 두경부 영 역의 수술 등이 있다..$^{2-5)}$ 최근에는 두경부에 반복적인 방사선 치료를 받거나 치상돌기로 암조직이 침범한 경우에도 발생하 는 것으로 알려져 있다. ${ }^{6.7)}$ 그러나 아직까지 국내에 이비인후과 질환과 관련하여 발생한 비외상성 환-축추 관절 아탈구가 문 헌상으로 보고된 경우는 없으며, 특히 방사선 치료를 받은 편
도암 환자에서 편도절제술 이후 발생한 증례는 국내외적으로 보고된 바가 없다.

저자들은 유도항암화학요법과 순차적 방사선 치료를 받은 후 재발한 구개편도암 환자에서 구제수술 목적으로 편도선절 제술을 시행한 후 발생한 환-축추 관절 아탈구 1 예를 경험하 였기에 문헌 고찰과 함께 보고하는 바이다.

\section{증 례}

55세 남자 환자가 3개월 전부터 발생한 연하통을 주소로 방문하였다. 그 외에 다른 증상은 없었으며 과거력상 특이소 견은 없었다. 이학적 검사상 약 $3 \times 4 \mathrm{~cm}$ 크기의 딱딱한 궤양 성 종괴가 좌측 구개편도에 관찰되었다. 진단을 위해 조직검 


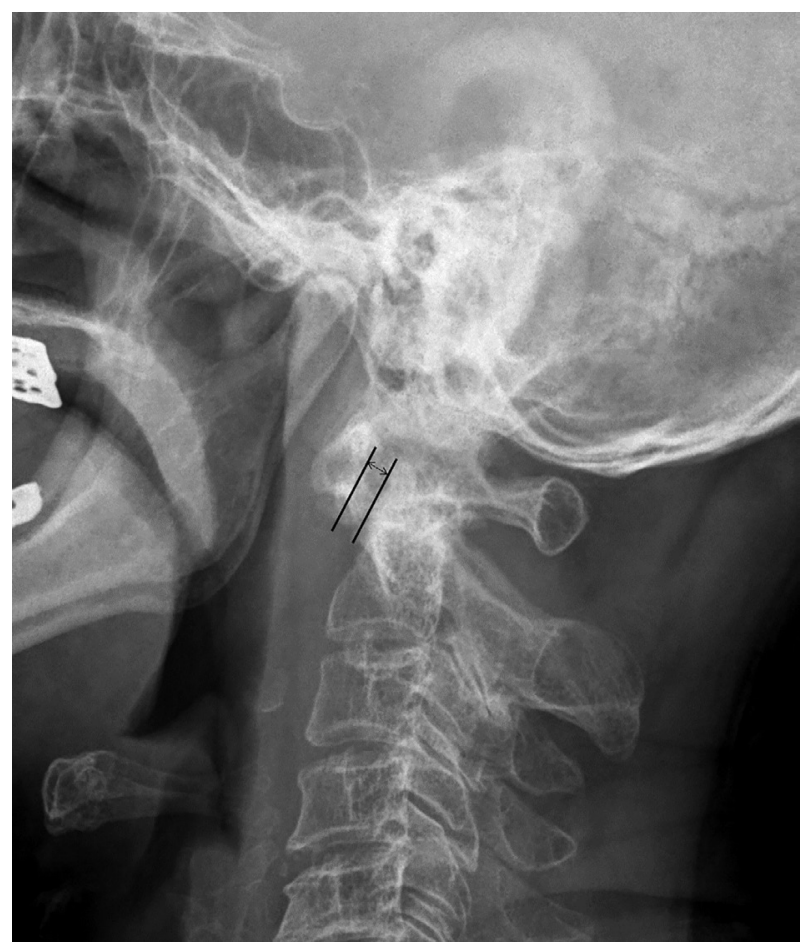

Fig. 1. Cervical spine lateral view shows straightened curvature of cervical vertebra, and widened atlanto-dental interval, measuring $4 \mathrm{~mm}$ (the gap of double headed arrow).
사를 시행하였고, 병리소견에서 중등도 분화를 가지는 침윤 성 편평세포암종으로 진단되었다. 경부 전산화단층촬영상 좌 측 편도가 우측에 비해 조금 크기가 증가된 소견 외에 특이소 견은 없었으며, 경부 림프절 전이는 보이지 않았다. 원격전이 여부를 확인하기 위해 식도조영술, 경부초음파, 복부초음파와 뼈스캔 등을 시행하였으나, 이상소견은 보이지 않았다. 최종적 으로 좌측 구개편도암 2 기 $\left(\mathrm{T}_{2} \mathrm{~N}_{0} \mathrm{M}_{0}\right)$ 로 진단하고, 수술적 치료 를 권유하였으나, 환자가 거부하여 cisplatin과 5-fluorouracil 을 이용한 유도항암화학요법을 2회 치료받은 후 구인두와 경 부에 33회에 걸쳐 총 $66 \mathrm{~Gy}$ 의 방사선 치료를 시행하였다. 그 러나, 방사선 치료 종료 후 3개월이 경과한 다음에도 원발부위 에 $1 \times 2 \mathrm{~cm}$ 크기의 종물이 지속적으로 관찰되어 전신마취 하 에 경구강 편도선절제술을 시행하였다. 수술은 전신마취 하에 개구기를 걸어 구개편도를 노출시킨 후에 전기소작기를 이용 하여 좌측 구개편도와 주위 연부조직을 일부 포함하여 절제 하였다. 환자는 합병증 없이 수술 후 2일째에 퇴원하였다.

환자는 1 개월 간격으로 경과관찰을 시행하였으며, 구강불 편감 외에 다른 증상은 없었다. 그러나, 수술 후 3 개월째 갑자 기 두통과 경부 움직임의 제한을 호소하였다. 이학적 검사상 후경부의 압통을 호소하였으나, 재발 및 전이를 의심할 만한

Fig. 2. Preoperative axial CT scan shows the stability of atlanto-axial joint well maintained (black arrow) (A). Postoperative axial CT scan shows a widened distance between the anterior arch of atlas and dens (black arrowheads), measuring 4 $\mathrm{mm}$ (B). T2-weighted sagittal view of cervical spine MRI shows a widened atlanto-dental interval with heterogenous hypointensity (white arrow) (C).
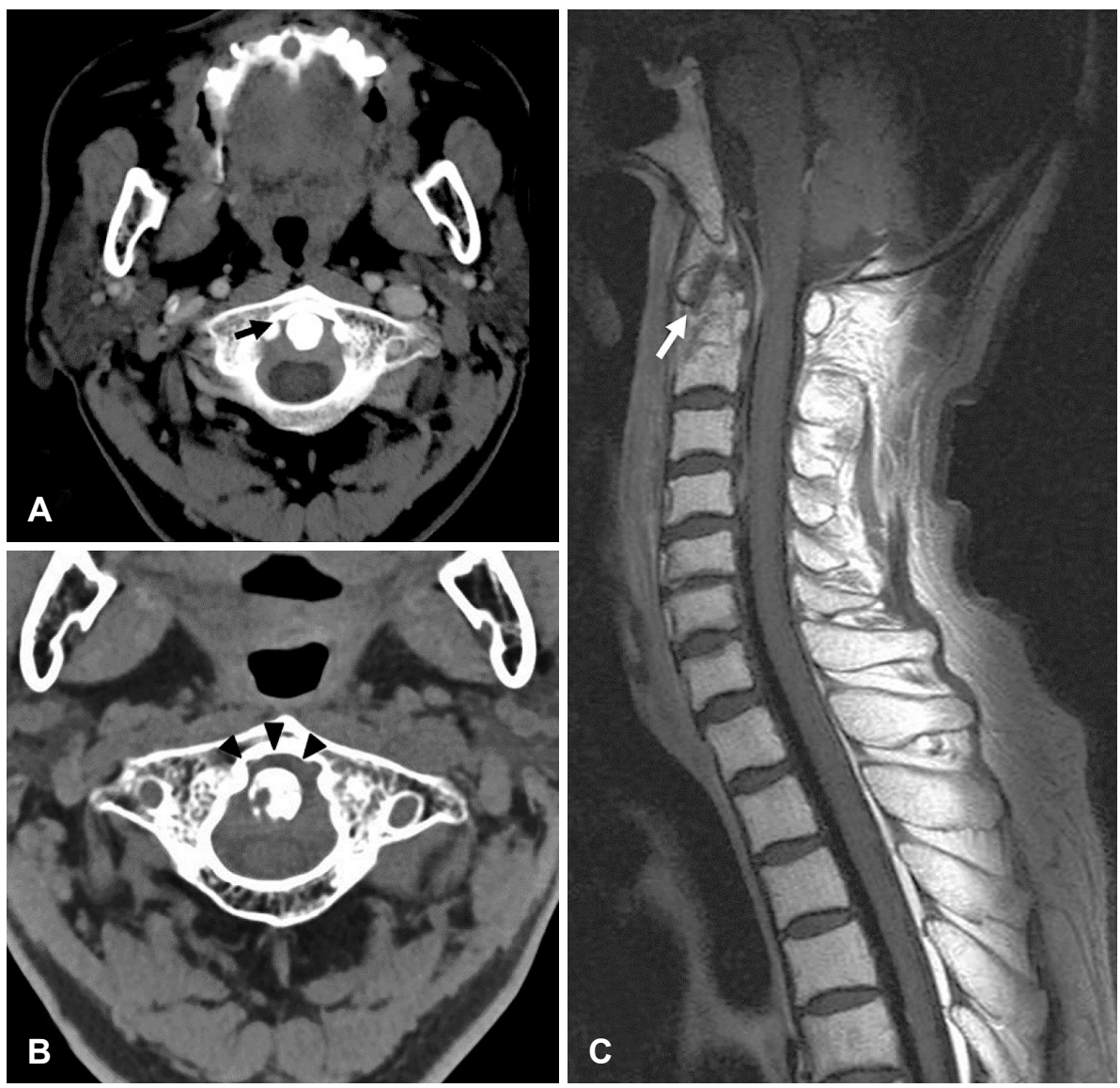

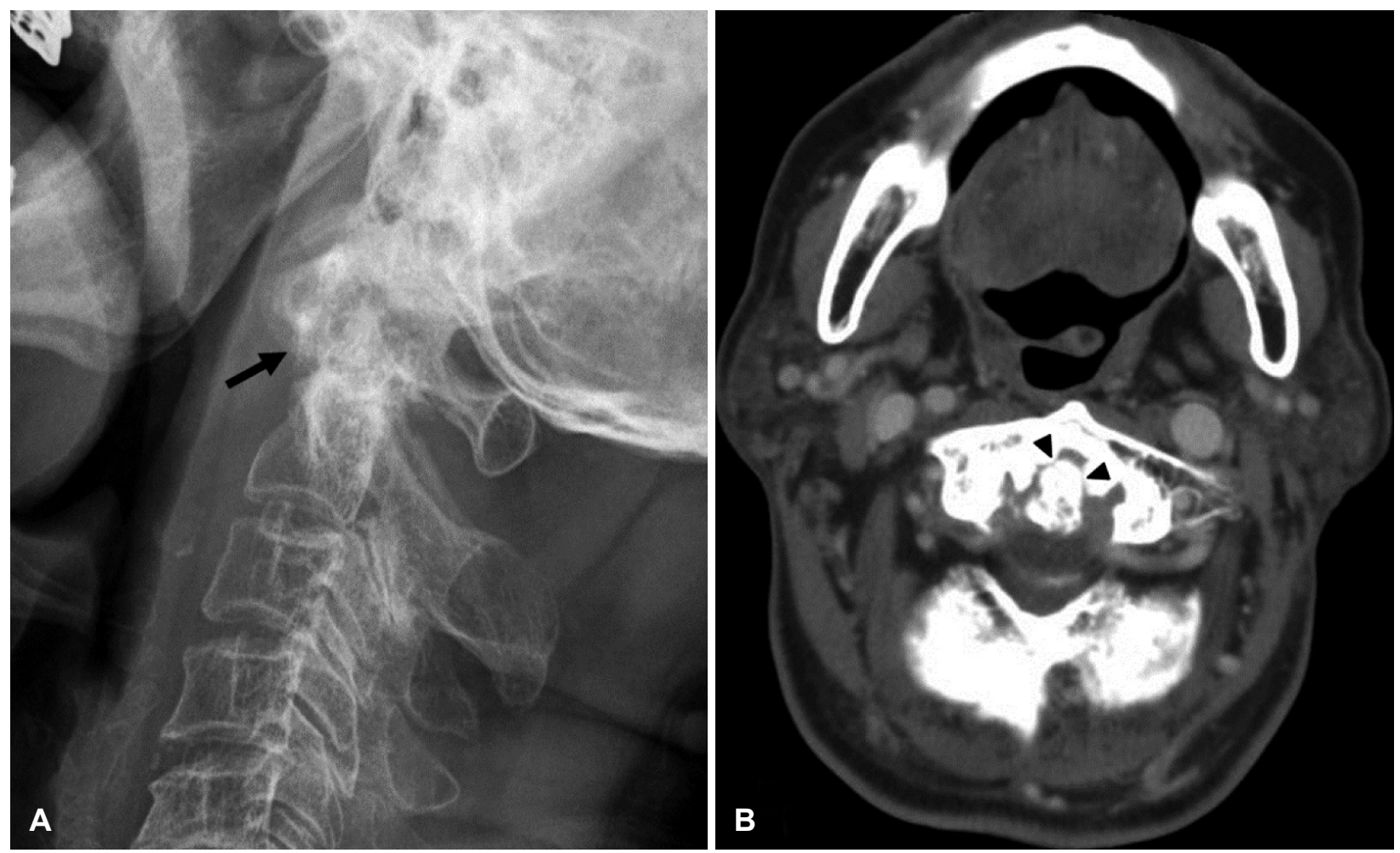

Fig. 3. After one year, cervical spine lateral view shows narrowed atlanto-dental interval (black arrow) and improved cervical curvature (A), axial CT scan shows attached atlas and dens (black arrowheads) (B).

소견은 보이지 않았고, 신경학적 이상소견도 관찰되지 않았다. 그러나, 측경부 단순방사선촬영상 환추와 치돌기간의 간격 (atlanto-dental interval)이 증가되어 있었으며, 경추의 정상적 굴곡이 소실되어 있었다(Fig. 1). 굴곡-신전 측면방사선촬영에 서는 환-축추 간에 약간의 가동성이 있었으나 신전에 의한 아 탈구의 정복은 경미하였다. 명확한 진단을 위해 척추 전산화 단층촬영검사와 자기공명영상검사를 시행하였으며, 전산화단 층촬영검사상 수술 전과 비교하여 환추-치돌기 간격이 $4 \mathrm{~mm}$ 정도 벌어져 있었고, 환-축추 관절의 회전고정이 확인되었다 (Fig. 2A and B). 자기공명영상검사에서는 환-축추 관절 부위 에 염증소견이 관찰되었으나, 척수의 압박은 보이지 않았다 (Fig. 2C). 이에 환-축추 관절 아탈구로 진단하고, 항생제와 근육이완제를 이용한 약물치료와 경추보장구를 착용하였다. 증상은 치료 후 2 개월 뒤 완전히 소실되었으며, 굴곡-신전 측 면 단순 방사선촬영에서도 환-축추 관절의 가동성 회복을 확 인할 수 있었고(Fig. $3 \mathrm{~A}$ ), 암의 경과를 보기 위해 1 년 후 시행 한 경부 전산화단층촬영에서도 환-축추 관절이 안정화되어 있음을 확인할 수 있었다(Fig. 3B).

\section{고 찰}

그리즐 증후군의 발생기전은 명확하지 않으나, 다양한 원인
으로 인해 발생한 환-축추 관절부위의 충혈과 염증반응이 환 추의 전궁의 골흡수와 횡인대의 비정상적 이완을 유발하여 발생하는 것으로 알려져 있다. ${ }^{1}$ 특히, 5 12세 사이의 소아에 서 주로 발생하며, 사경(torticollis), 경부강직 및 경부통증 등 이 주증상이다. ${ }^{3-5)}$ Bocciolini 등희 의 보고에 따르면, 가장 흔한 발생원인은 상부호흡기 감염, 편도선염, 중이염, 후인두부 농 양 등의 감염성 질환이며, 두 번째 흔한 원인은 이비인후과질 환과 관련된 수술이다. 그중 편도 및 아데노이드절제술 이후 발생한 경우가 25예 중 11예로 가장 많았으며, 유양동절제술 후 발생한 경우가 9예로 두 번째로 많았다. 또한, 드물지만 비 인강암이나 척수내 종양과 같이 환-축추 관절부위가 방사능 조사영역에 포함되는 방사선 치료를 받은 환자에서도 발생하 는 것으로 알려져 있다. ${ }^{6-8)}$

본 증례의 환자는 수술 전에 경부 방사선 치료를 받았다. 특 히, 원발암이 좌측 편도상극과 연구개 일부를 침범하고 있어 방사선 조사범위에 환-축추 관절부위가 포함되었다. 또한, 잔 여 원발암의 절제를 위해 경부를 과신전 시킴으로써 약해져 있던 환-축추 관절에 과도한 힘이 가해져 아탈구가 유발되었 을 것으로 생각된다. 이는 성인 환자에서 편도절제술 후 환축추 관절 아탈구가 발생한 매우 드문 경우이며, 수술 전 방사 선 치료가 질환 발생에 큰 영향을 주었을 것으로 생각된다.

그리즐 증후군 환자는 사경, 경부강직, 경부 움직임 장애, 
경부통증, 사지마비 등 다양한 증상을 호소한다. 특히 사경은 매우 특징적인 임상 증상이다. 그러나, Kerolus 등 ${ }^{9}$ 의 보고에 따르면, 본 증례처럼 성인의 경우 소아와 달리 경부통증과 같 은 비특이적인 증상만을 호소하는 경우가 많았으며, 사경이 동반된 경우는 드물었다. 또한, 증상이 발생하는 시점도 수주 에서 수개월까지 다양하였다. 이는 성인과 소아의 환-축추 관 절 구조적 안정성 차이 때문으로 생각된다.

본 증례의 환자의 경우도 수술 후 3 개월 전까지 특이한 증 상을 보이지 않았으며, 후경부 압통과 경부 움직임 제한과 통 증 등의 비특이적 소견만 보였다. 그로 인해 임상적 소견만으 로 진단이 어려워 추가적인 영상학적 검사를 통해 그리즐 증 후군으로 진단할 수 있었다.

그리즐 증후군의 명확한 진단은 영상학적 검사를 통해 이 루어진다. 경추의 최대 굴곡상태에서 정상적인 환추-치돌기 간격(atlanto-dental interval)은 소아에서는 $5 \mathrm{~mm}$ 이하, 성인 에서는 $3 \mathrm{~mm}$ 이하이며, 이를 넘을 경우 의심할 수 있다. ${ }^{10,11)}$ 전산화단층촬영이나 자기공명영상은 환-축추 관절의 세밀한 부분까지 확인할 수 있어 진단에 많은 도움을 주기 때문에 환-축추 아탈구가 의심되는 환자에서 확진을 위해 일반적으 로 시행된다. 영상학적 소견을 기반으로 Fielding 등리은 환축추 관절 아탈구를 4 가지 유형으로 나누어 분류하였는데, 이 는 질환의 예후와 합병증 발생 가능성을 예측하는 중요한 척 도로 현재 사용되고 있다. 제 1 형은 실질적인 아탈구가 아닌 정 상적인 범위 내의 회전 고정(rotary fixation)을 말하며 횡인대 는 정상인 경우이다. 제2형은 관절의 편측이 전방으로 전위된 경우로 건측은 선회축(pivot) 역할을 하고, 환추 전위는 3 5 $\mathrm{mm}$ 정도이다. 제 3 형은 양측의 횡인대와 익상 인대의 결손으 로 인해 양측이 전방 전위된 것을 말하며, 환추 전위는 $5 \mathrm{~mm}$ 이상이다. 제4형은 환추가 후방으로 전위된 경우로 이러한 경 우는 매우 드물다(Table 1). 본 증례는 환자의 증상, 이하적 소 견 및 단순방사선검사를 통해 환-축추 관절 아탈구를 의심하 였으며, 전산화단층촬영과 자기공명영상을 통해 제2형 환-축 추 관절 아탈구로 확진된 경우였다.

그리즐 증후군의 치료원칙은 감염의 완전한 제거와 골격구 조의 회복, 그리고 척추신경의 보호이다. 단기간의 경부의 운

Table 1. Classification of Grisel's syndrome according to fielding

\begin{tabular}{cc}
\hline Type & \multicolumn{1}{c}{ Description } \\
\hline I & $\begin{array}{c}\text { Rotatory fixation without anterior displacement } \\
\text { of atlas } \leq 3 \mathrm{~mm}\end{array}$ \\
II $\quad \begin{array}{c}\text { Rotatory fixation with anterior displacement } \\
\text { of atlas of } 3-5 \mathrm{~mm}\end{array}$ \\
III $\quad \begin{array}{c}\text { Rotatory fixation with anterior displacement } \\
\text { of atlas }>5 \mathrm{~mm}\end{array}$ \\
IV $\quad$ Rotatory fixation with posterior displacement of atlas \\
\hline
\end{tabular}

동제한이 있는 아탈구 환자의 대부분은 Fielding 등 ${ }^{12)}$ 분류의 제 1 형과 제 2 형에 해당하며, 이 경우 침상안정, 근육이완제, 경 추보장구를 이용한 목의 고정 등의 보존적 치료를 시행하고, 감염으로 인한 원인일 경우 항생제 치료를 함께 시행한다. 조 기에 진단하여 치료하는 경우 효과는 매우 탁월하며 좋은 예 후를 보이지만, 증상이 발생하고 1 개월 이상 경과하여 수술적 교정이 필요한 경우 대부분 환-축추의 가동성을 잃게 된다. 또한, 드물지만 제3형과 제4형과 같이 심한 아탈구가 발생하게 되면 척추압박을 유발하는 경우가 많아 심각한 합병증을 초 래하기도 한다. 본 증례에서는 영상학적 검사로 제2형 환-축 추 관절 아탈구로 확진하여 약물치료와 경추보장구를 이용한 보전적 치료를 통해 좋은 결과를 얻을 수 있었다.

그리즐 증후군의 예후는 대체로 좋지만, 치료가 지연되면 기능적, 미용적 후유증이 남을 수 있고, 심한 경우 척수의 압 박으로 인해 신경마비나 사망 등의 심각한 합병증이 초래될 수 있어 드물지만 매우 위험한 질환이다. ${ }^{5)}$ 특히, 환자의 나이 가 어리거나, 최근 감염성 경부질환을 않은 환자, 과거 경부 방 사선 치료의 과거력이 있는 환자의 경우 발생할 가능성이 높 다. 그러므로, 이러한 위험성을 가진 환자들에게는 환-축추 관절의 안정성에 영향을 줄 수 있는 경부 과신전, 비인두벽의 과도한 소작, 감염된 조직을 통한 마취제 주입 등과 같은 처치 를 하지 않도록 주의를 기울여야 하며, 방사선 치료를 받은 두 경부암 환자에서 경부통증과 움직임 제한이 갑자기 발생할 경 우 그리즐 증후군의 가능성도 고려해보아야 하겠다.

\section{REFERENCES}

1) Guleryuz A, Bagdatoglu C, Duce MN, Talas DU, Celikbas H, Köksel T. Grisel's syndrome. J Clin Neurosci 2002;9(1):81-4.

2) Deichmueller CM, Welkoborsky HJ. Grisel's syndrome--a rare complication following "small" operations and infections in the ENT region. Eur Arch Otorhinolaryngol 2010;267(9):1467-73.

3) Bocciolini C, Dall'Olio D, Cunsolo E, Cavazzuti PP, Laudadio P. Grisel's syndrome: a rare complication following adenoidectomy. Acta Otorhinolaryngol Ital 2005;25(4):245-9.

4) Rinaldo A, Mondin V, Suárez C, Genden EM, Ferlito A. Grisel's syndrome in head and neck practice. Oral Oncol 2005;41(10):966-70.

5) Karkos PD, Benton J, Leong SC, Mushi E, Sivaji N, Assimakopoulos DA. Grisel's syndrome in otolaryngology: a systematic review. Int J Pediatr Otorhinolaryngol 2007;71(12):1823-7.

6) Cheung JP, Wei WI, Luk KD. Cervical spine complications after treatment of nasopharyngeal carcinoma. Eur Spine J 2013;22(3):584-92.

7) Tiruchelvarayan R, Lee KA, Ng I. Surgery for atlanto-axial(C1-2) involvement or instability in nasopharyngeal carcinoma patients. Singapore Med J 2012;53(6):416-21.

8) Fletcher DT, Warner WC, Muhlbauer MS, Merchant TE. Cervical subluxation after surgery and irradiation of childhood ependymoma. Pediatr Neurosurg 2002;36(4):189-96.

9) Kerolus M, Jeans EB, Fontes RB, Deutsch H, Traynelis VC. Atlantoaxial instability of inflammatory origin in adults: case reports, literature review, and rationale for early surgical intervention. Neurosurgery 2015;76(2):E226-32; discussion E232.

10) Locke GR, Gardner JI, Van Epps EF. Atlas-dens interval(ADI) in 
children: a survey based on 200 normal cervical spines. Am J Roentgenol Radium Ther Nucl Med 1966;97(1):135-40.

11) Floman Y, Kaplan L, Elidan J, Umansky F. Transverse ligament rupture and atlanto-axial subluxation in children. J Bone Joint Surg
Br 1991;73(4):640-3.

12) Fielding JW, Hawkins RJ, Hensinger RN, Francis WR. Atlantoaxial rotary deformities. Orthop Clin North Am 1978;9(4):955-67. 